\title{
Study Regarding the Inhibition of Acetylcholinesterase by Isopropyl 4-Nitrophenyl Methylphosphonate
}

\author{
Tudor V Tiganescu ${ }^{1}$, Raluca E Ginghina*2, Nicoleta Grigoriu*2, Mihaela Muresan², Constantin N Toader ${ }^{2}$ \\ and Bogdan Patrinichi ${ }^{3}$ \\ ${ }^{1}$ Military Equipment and Technologies Research Agency, Romania \\ ${ }^{2}$ Scientific Research Center for CBRN Defense and Ecology, Romania \\ ${ }^{3}$ Military Medical Research Institute, Romania \\ *Corresponding author: Nicoleta Grigoriu, Scientific Research Center for CBRN Defense and Ecology, Romania \\ Raluca E Ginghina, Scientific Research Center for CBRN Defense end Ecology, Romania
}

\begin{abstract}
ARTICLE INFO
Received: 幽 February 04, 2019

Published: 幽 February 11, 2019

Citation: Nicoleta Grigoriu. Study Regarding the Inhibition of Acetylcholinesterase by Isopropyl 4-Nitrophenyl Methylphosphonate. Biomed J Sci \& Tech Res 14(2)-2019. BJSTR. MS.ID.002540.

ABSTRACT

At present, many scientific institutions around the world are interested in the synthesis and improvement of new antidotes against Chemical Warfare Agents (CWAs), especially nerve agents, because of the continuous threat of the nerve agent misuse by terrorists. Few studies have been published concerning the reactivity of CWAs due to the danger of conducting such experiments, the limited laboratory supply of CWAs and the classified nature of the materials. The inherent toxicity and limited laboratory supply of CWAs has led to the development and study of safer compounds that simulate the chemistry and the reactivity of CWAs. Antidotes as Acetylcholinesterase (AChE) reactivators containing oxime groups have been demonstrated to be effective for the breakdown of nerve agents and/or their simulants. The study proposes a simulant for sarin, for experimental
\end{abstract}

Abbreviations: AChE: Acetylcholinesterase; NIMP: Isopropyl 4-Nitrophenyl Methylphosphonate; LD50: Median Lethal Dose
Keywords: Isopropyl 4-Nitrophenyl Methylphosphonate; Arin; Chemical Warfare Agents; Ache Inhibition

\section{Introduction}

C10H14NO5P, MW 259 methylphosphonate
Figure 1: Structures of nerve agent (sarin) and the
corresponding simulant (NIMP) used in the biological
study.

Isopropyl 4-Nitrophenyl Methylphosphonate (NIMP) [1,2], a sarin simulant, was synthesized for testing the AChE inhibition capacity, in order to find it as suitable chemical simulant [3] for sarin
(Figures 1 \& 2). In vivo pharmacotoxicological experimental study of the above presented chemical compound was performed in order to determine its LD50 value, the degree of cholinesterase inhibition lethal doses appropriate, and the oxime assisted protective ration case of poisoning. To determine the LD50 and index protection defined as the ratio of LD50 the lot poisoning CWA simulant and treated and LD50 the lot intoxicated and untreated, there were used laboratory animals (rats Wistar) distributed in homogenous groups (intoxicated, treated and batch control). Monitoring of animals during the experiment was to record the moment signs of intoxication, mortality recording 60 minutes, 24 hours after poisoning the lots intoxicated and intoxicated and treated, tracking and recording time appearance remission signs of intoxication lots intoxicated and treated. The AChE activity was measured by using the standardised bioanalytical method performed by Eyer \& Woreck in 2001. The used specimen was rat heparinised blood 
collected by venous punction. A UV/VIS Perkin Elmer Spectrometer equipped with soft UV KinLab. Lambda 40 was used as measuring equipment. Experimental data statistical analysis was performed by using Student's T test and One Way Anova test.
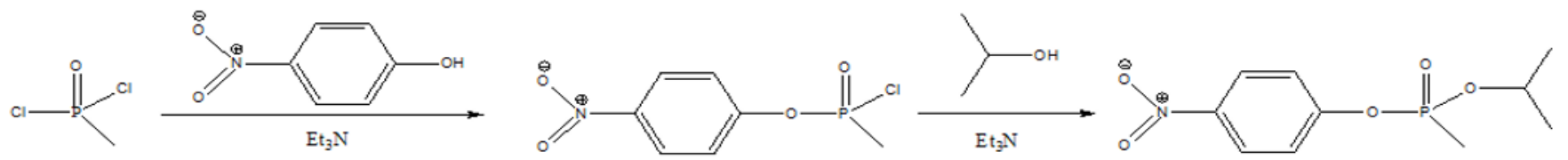

Figure 2: NIMP general synthesis reaction.

\section{Experimental Results}

Inhibition of erythrocyte [4] AChE due to the studied compound three doses in the range of logarithmic progression of the points, showed a related to dose pharmacodynamic effect between $53 \%$ and $95 \%$, values like those of the reference compound. NIMP doses in the range of $\operatorname{LD} 50(0.59,0.47$, and $0.31 \mathrm{mg} / \mathrm{kg}$ i.p.) leads to 95 , 87, and 53\% of AChE inhibition, comparable to the AChE inhibition values determined by the appropriate range LD50 of nerve agent correspondent, sarin. The experimental data are presented in the Figure 3. The calculated LD50 values by using our experimental data was $0.45 \pm 0.002 \mathrm{mg} / \mathrm{kg}$ i.p. (reference range 0.31 to 0.59 $\mathrm{mg} / \mathrm{kg}$ i.p.) for NIMP. The regression equation and the correlation coefficient calculation results in NIMP LD50 are presented in the Figure 4. The determination of the protection ratio, linear regression and correlation coefficient are represented in Figure 5 and (Table 1).

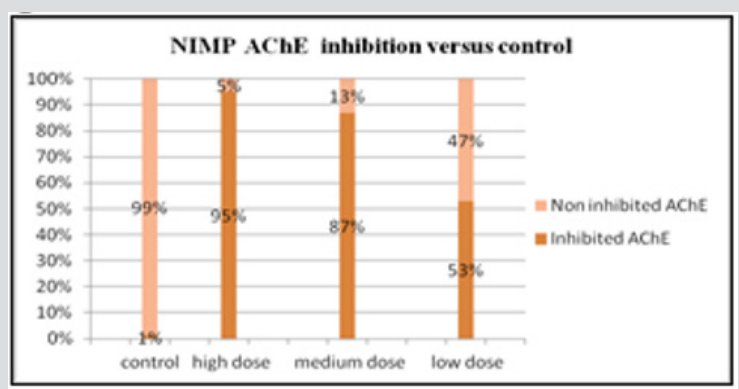

Figure 3: Structures of nerve agent (sarin) and the corresponding simulant (NIMP) used in the biological study.

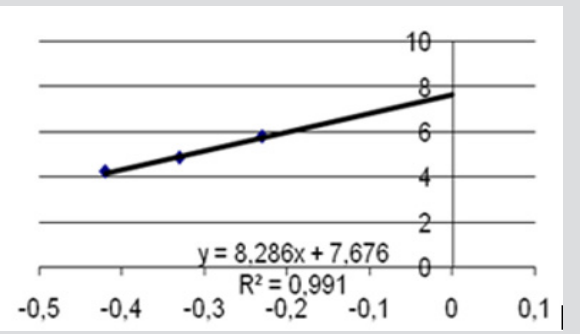

Figure 4: The regression equation and the correlation coefficient calculation results in NIMP LD50; $X$ axislogarithmic values of doses administered 3 groups introduced in the experiment; $\mathrm{Y}$ axis- values of the probit corresponding to mortality percentage.

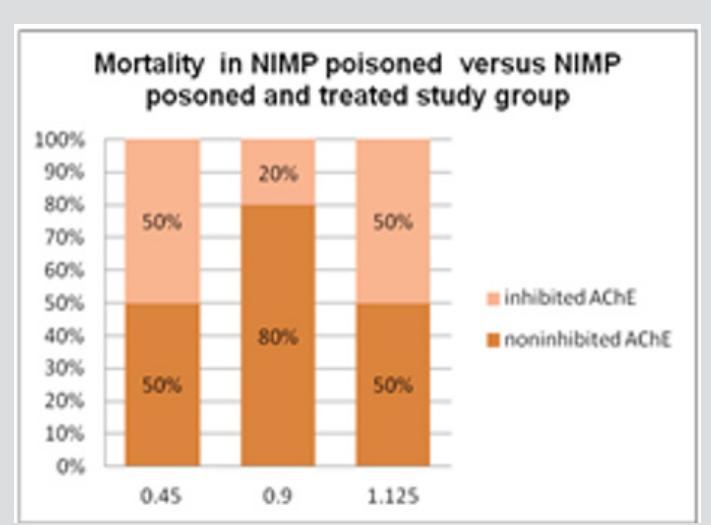

Figure 5: Highlighting experimental data of mortality in calculating the protective ratio in case of NIMP poisoning: $0.45 \mathrm{mg} / \mathrm{kg}$ NIMP LD50 doses administrated to the poisoned and untreated study group; $1.125 \mathrm{mg} / \mathrm{kg}$ NIMP LD50 doses administrated to the poisoned and oxime assisted study group.

Table 1: Highlighting experimental data of mortality in calculating the protective ratio in case of NIMP poisoning: $0.45 \mathrm{mg} / \mathrm{kg}$ NIMP LD50 doses administrated to the poisoned and untreated study group; $1.125 \mathrm{mg} / \mathrm{kg}$ NIMP LD50 doses administrated to the poisoned and oxime assisted study group.

\begin{tabular}{|c|c|c|c|c|c|}
\hline Lotno. & $\begin{array}{c}\text { NIMP doses } \\
\text { mg/kg i.p. }\end{array}$ & $\begin{array}{c}\text { Atropine } \\
\text { doses mg/ } \\
\text { kg i.m. }\end{array}$ & \multicolumn{2}{|c|}{$\begin{array}{c}\text { Obidoxime } \\
\text { Mortality mg/kg } \\
\text { i.m.\% }\end{array}$} & $\begin{array}{c}\text { Protective } \\
\text { ratio }\end{array}$ \\
\hline 7 & 0.45 & 17.5 & 250 & 0 & 1 \\
\hline 8 & 0.9 & 17.5 & 250 & 20 & 2 \\
\hline 9 & 1.125 & 17.5 & 250 & 50 & 2.5 \\
\hline 10 & 1.35 & 17.5 & 250 & 80 & 3 \\
\hline
\end{tabular}

\section{Conclusion}

The study showed that the percentage of inhibited AChE is comparable with the sarin one. Comparative analysis of LD50 values for NIMP and the correspondent nerve agent, showed lower intrinsec toxicity of the synthesized simulant. The protective ratio of antidote therapy (atropine, obidoxime) in the groups exposed to NIMP was I.P. $=2.5$, value comparable with the sarin one. Also, the enzymatic AChE reactivation value was comparable to the relevant reference substance levels. Inhibiting activity of this nerve agent simulant is enough to mimic exposure to real agents, being present all the clinical signs typical of poisoning. As with aging sarin related acetylcholinesterase, simulants show a slower rate of aging, 
prolonging survival time and allowing therapeutic window for reactivating oximes. Thus, it can be concluded that the compound studied shows similar pharmacodynamic effects and references due to lower intrinsic toxicity may be suitable as a simulant for research studies in the laboratory activities.

\section{References}

1. Koskela, H, Grigoriu, N, Vanninen, P (2006) Screening and identification of organophosphorus compounds related to the chemical weapons convention with $1 \mathrm{~d}$ and $2 \mathrm{~d}$ nmr spectroscopy. Anal Chem 78(11): 3715 -3722 .

\section{ISSN: 2574-1241}

DOI: 10.26717.BJSTR.2019.14.002539

Nicoleta Grigoriu. Biomed J Sci \& Tech Res

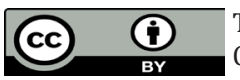

This work is licensed under Creative Commons Attribution 4.0 License

Submission Link: https://biomedres.us/submit-manuscript.php
2. Y Ashani, RD Gupta, M Goldsmith, I Silman, JL Sussman, et al. (2010) Stereo-specific synthesis of analogs of nerve agents and their utilization for selection and characterization of paraoxonase catalytic scavengers. Chem Biol Interact 187(1-3): 362-369.

3. EC Meek, HW Chambers, A Coban, KE Funck, RB Pringle, et al. (2012) Synthesis and in vitro and in vivo inhibition potencies of highly relevant nerve agent surrogates. Toxicol Sci 126(2): 525-533.

4. H Ohta, T Ohmori, S Suzuki, H Ikegaya, K Sakurada, et al. (2006) New safe method for preparation of sarin-exposed human erythrocytes acetylcholinesterase using non-toxic and stable sarin analogue isopropyl p-nitrophenyl methylphosphonate and its application to evaluation of nerve agent antidotes. Pharm Res 23(12): 2827-2833.

\begin{tabular}{ll} 
BIOMEDICAL & Assets of Publishing with us \\
RESEARCHES & - Global archiving of articles \\
& - Immediate, unrestricted online access \\
\hline
\end{tabular}

